\title{
Students' Motivation to Engage with Science Learning Activities through the Lens of Self-Determination Theory: Results from a Single-Case School-Based Study
}

\author{
Roger Wood ${ }^{1 *}$ \\ ${ }^{1}$ School of Education, University of Aberdeen, UK
}

Received 8 May 2018 - Revised 3 January 2019 - Accepted 11 January 2019

\begin{abstract}
Self-Determination Theory (SDT) is a sociocultural motivational theory that has been extensively applied within schools as a means of developing teachers' evidence-based practice, where the satisfaction of three basic psychological needs for relatedness, competence and autonomy has positive impacts upon students' motivation to engage with classroom-based learning activities. SDT has proved to be an effective theory for suggesting why selected key classroom-based behaviours and variables influence the students' engagement more than others. Whilst SDT emphasizes the centrality of autonomous motivation to students' engagement with scientific learning, it may be such engagement is more likely to be an outcome of students' perceived competence and teacher-student relationship quality. This potential outcome was explored through focus group interviews with 70 students, aged between 9 and 13. The responses consistently revealed key common variables that the students regarded the quality of the teacher-student relationship as being influential upon their perceptions of the teacher's effectiveness at enhancing students' perceived competence as opposed to satisfying any wish they had for their teacher to be autonomy-supportive. Such perceptions were consistently self-reported as being influential upon their engagement with, in this case, science-based learning activities.
\end{abstract}

Keywords: self-determination theory, student motivation, student engagement, perceived competence, teacher-student relationship quality, science education

\section{INTRODUCTION}

Teachers are the key factor in motivating students to engage with learning activities within their specific educational contexts (Ryan and Deci, 2009). A teacher whose behaviours reveal a positive attitude and enthusiasm for learning within a specific curricula subject is more likely to have students who develop positive affect and enthusiasm for learning and achievement within the subject (Fredricks et al., 2004; Tymms et al., 2008). Teachers' ability to engage students' interest and participation in their schooling in general (Christenson et al., 2012; Klem and Connell, 2004; Skinner and Belmont, 1993) is regarded as essential for a sustained academic achievement (Christenson et al., 2012; Fredricks et al., 2004; Marsh and Martin, 2011; Reeve, 2002, 2012).

Prior research suggests that " $\ldots$ at the classroom level, teacher support, positive teacher-student relationships ... autonomy support and authentic and challenging tasks have been associated with student engagement" (van Uden et al., 2013, p. 44). Three essential factors consistently emerge as having a positive influence upon the optimal development of students' self-regulated academic motivation and achievement within classroom learning activities (Connell and Wellborn, 1991; Hattie, 2012). These are the quality of teacher-student interpersonal relationships, the extent to which learning activities are autonomously directed by students, and the nature and timing of competence-related feedback given by the teacher to the student. Within the research reported here, student engagement has been approached as an outcome of motivational informants, taking the form of a combination of observable behaviours and self-reported affect-driven perceptions (Christenson et al., 2012; Fredricks et al., 2004;

(C) 2019 by the authors; licensee Modestum Ltd., UK. This article is an open access article distributed under the terms and conditions of the Creative Commons Attribution License (http://creativecommons.org/licenses/by/4.0/). \dwood@brookes.ac.uk (*Correspondence) 


\section{Contribution of this paper to the literature}

- The current research posits that student engagement is an outcome manifested in response to the motivation that students gain from the teacher satisfying the need for competence or autonomy, or both. A hierarchy amongst types of engagement has previously been proposed by Reschly and Christenson (2006, 2012) in that they argue that cognitive and emotional engagement precede and inform the quality and persistence of behavioural engagement.

- The evidence and interpretations within the current research are significant in that it reveals studentreported means of informing teachers' understanding of how they have and can have a direct impact upon their students' motivated engagement.

- This understanding may be used to inform practitioners' evidence-based practice. For example, these identified factors and the associated understanding of the interplay between them may be used in the design and implementation of interventions with the objective of teachers successfully enhancing their students' engagement with learning.

Klem and Connell, 2004; NRC, 2004). These perceptions and their informants are common to the three needs within Self-Determination Theory (SDT: Ryan and Deci, 2000a).

The research discussed herein utilized SDT as a theoretical lens for identifying and interpreting some of the key contextual variables that enhance students' self-determined engagement with learning activities. The research question - What do students regard as the key influences that have an impact upon their motivated engagement with learning activities? - led to a focus upon variables included teacher behaviours and methods that have a positive impact upon students' motivation to engage with learning, such as students' perceptions of the quality of the teacher-student relationship. SDT is a sociocultural motivational theory that has been effectively applied within schools as a means of developing teachers' evidence-based practice (Ryan and Deci, 2009), where the satisfaction of three basic psychological needs (BPNs: relatedness, competence and autonomy) has positive impacts upon students' motivation to engage with learning activities. Indeed, SDT has been empirically shown to be an effective theory for explaining why some key classroom-based behaviours and variables influence the students' engagement more than others (Reeve, 2002, 2012). Fredricks et al., (2004) note that the degree to which the three SDT needs mediate between teacher behaviour contextual factors and engagement had not been investigated by most studies seeking to understand engagement, and that least studied are the motivational relationships between perceived competence and students' persistent engagement with learning (p. 82). The research outlined here is one contribution to reducing such a paucity of studies.

\section{LITERATURE REVIEW}

Motivation has been defined as a cognitive and affective force that initiates, sustains and directs engagement behaviours, as an internalised process of formation drawn from the individual's experiences, perceptions and interpretations (Reeve, 2012). It consists of an inner psychological drive leading to action, i.e. engagement behaviours (Abrahams, 2011; Bandura, 1986). Engagement is defined as a motivation-driven mental construct predictive of and predicted by students' perceptions of positive interpersonal relationships (relatedness) at school in tandem with the cognitive and affective desire to initiate and sustain participation in a range of learning contexts and activities therein (Fredricks et al, 2004). Engagement is observable as manifestations of the motivated desire to be involved within learning activities. Engagement has been argued as being synonymous with self-regulated learning through motivation-informed and driven desires or needs, as common behaviours include persistence, attitude, concentration, the management of time, focus upon the main ideas and objectives, and the processing of information (de Bilde et al, 2011; Zimmerman and Schunk, 2008). Fredricks et al. (2004) discuss three other forms of engagement - affective, behavioural and cognitive: however, for simplicity, this study primarily focuses upon motivational leading to behavioural engagement: that is, prosocial behaviours exhibited through participation in school-based activities, and involvement in, for example, related extra-curricular activities and actively studying a subject area beyond the classroom out of personal interest (NRC, 2004). Parsons and Taylor (2011) cite three substantive reasons for researching and understanding the motivational processes and influences that impact upon student engagement: defining different types of engagement and their observable indicators;

“... to help disengaged and disadvantaged students achieve and participate (or to reduce drop outs); to assist in classroom management (reduce classroom disruptions and discipline issues); and, finally, to engage students in learning about learning (to help them to become skilled life-long learners as opposed to well-behaved, attentive students)." 
Student engagement is, therefore, of immense significance within classrooms as a measurable multidimensional construct in the form of a dynamic, malleable outcome of students' motivation for learning through affective, verbal and behavioural responses that are, reciprocally, predictive of students' motivational inclinations (Klem and Connell, 2004; NRC, 2004). Engagement has been posited as a significant predictor and indicator of students' motivation and well-being within formal learning environments (Baumeister and Vohs, 2007; Fredricks et al., 2004; Ryan and Deci, 2009). Therefore, students' engagement with learning in general is regarded as essential for the long-term commitment of students to their learning goals and prosocial approaches to academic success (Fredricks et al., 2004; Lawson and Lawson, 2013; Reeve, 2002, 2012). The converse of engagement is disengagement (also known as disaffection). Disengagement has been empirically asserted to be a cause of increased school drop-out rates, reduced attendance levels, and ultimately students not achieving their own self-perceived or their teacherregarded potential $(\mathrm{OECD}, 2000)$. As engagement has a positive association with improved educational outcomes such as achievement levels, for teachers, "... the primary appeal of the engagement construct is that it is relevant for all students." (Christenson et al., 2012, p. vii) With regards to academic achievement and enjoyment of learning, "... considerable evidence now reveals that students who are intrinsically motivated and inherently interested or engaged in the learning process will more effectively master classroom assignments and achieve at higher levels" (Harter, 2012a, p. 273).

The three most frequently mentioned forms of engagement within classroom-based learning are affective engagement, cognitive engagement and behavioural engagement (Fredricks et al., 2004; Fredricks and Eccles, 2002; Parsons and Taylor, 2011). In addition, a further form of engagement - agentic engagement - has recently been proposed by Reeve and Tseng (2011). Affective, cognitive and behaviours engagement are asserted as combining to inform behaviours indicative of student engagement within classroom-based learning (NRC, 2004). However, Reeve (2012) proposes that all four subtypes of student engagement should be considered together when seeking to understand and enhance students' academic engagement. Within each, engagement behaviours are viewed as initiated by psychological responses and physical actions underpinned by motivational constructs (Connell and Wellborn, 1991; Deci and Ryan, 1985; Reschly and Christenson, 2012; Skinner and Pitzer, 2012).

Affective engagement "... encompasses positive and negative reactions to teachers, classmates, academics, and school and is presumed to create ties to an institution and influence willingness to do the work" (Fredricks et al., 2004, p. 60). Indicators of positive affective engagement during learning activities include enthusiasm, interest, enjoyment, satisfaction, pride, vitality and zest (Ryan and Deci, 2008; Skinner and Pitzer, 2012). Conversely, indicators of affective disaffection include boredom, disinterest, frustration, anger, sadness, worry, anxiety, shame and self-blame (Skinner and Pitzer, 2012, p. 25). Behavioural indicators of positive affective engagement include excitement, elation, happiness, hope, joy, pride and gratitude. Negative indicators include tension, anger, sadness, frustration, anxiety and shame (Pekrun and Linnenbrink-Garcia, 2012, pp. 261 - 262).

Cognitive engagement consists of inherently different internal psychological processes from those of affective engagement. Cognitive engagement acts as the mediating bridge between context and learning outcomes (Connell and Wellborn, 1991; Reschly and Christenson, 2012). Cognitive engagement has been defined as drawing "... on the idea of investment; it incorporates thoughtfulness and willingness to exert the effort necessary to comprehend complex ideas and master difficult skills" (Fredricks et al., 2004, p. 60). Indicators of positive cognitive engagement include observations that a student is purposeful, approaches learning activities with enthusiasm, strives to achieve a variety of learning goals, is a willing participant in learning activities, actively seeks challenges, and exhibits a thoroughness and desire to achieve the best possible learning outcomes (Skinner and Pitzer, 2012). Indicators of cognitive disengagement include a lack of self-direction, presenting themselves as helpless, unwilling or opposed to tackling learning challenges, avoiding or being apathetic during learning activities, and presenting themselves as incapable, incompetent or under undue pressure (Skinner and Pitzer, 2012).

Agentic engagement centres upon the active and volitional cognitive contributions that students make to learning activities (Reeve and Tseng, 2011). Agentic engagement is asserted as predictive of cognitive, affective and behavioural engagement, as well as an independent predictor of achievement within the classroom, particularly in terms of students feeling empowered to make constructive contributions to their learning activities (Reeve, 2013; Reeve and Tseng, 2011).

Motivation and engagement are usually dependent on an individual's self-perceptions of their actual achievements and perceived competence (Schunk and Pajares, 2005). These two perceptions are purported to act as motivational precursors of self-efficacy, which act, in turn, as predictors of sustained and effortful engagement within an activity (Bandura, 1997). Such engagement involves the expenditure and sustaining of effort which is optimally catalysed when the causes of competence are regarded as controllable. Zimmerman (1995) states that the evolution and sustaining of academic competencies is one of the most demanding motivational and cognitive challenges that developing children face (p. 202). Such perceptions of competence are constantly evolving and are usually informed by factors such as feedback from teachers, personal aspirations, intrinsically motivated goals, selfendorsed values, and a self-determined approach to activities through perceived autonomy-orientated causation. 
All are informed by and internalised through context-specific experiences and self-perceptions (Reeve, 2012). These may act as the causality orientations within learning contexts, and, especially, a student's predictions regarding a teacher's verbal and non-verbal responses to the student's efforts and achievement. From perceived verbal and behavioural indicators of teacher warmth and expectation, each individual student will form their own worldview of a teacher based upon their experience of prior interactions. This appears to inform a student's perception of the strength of their attachment to each of their teachers, and is likely to influence future responses to the teacher and learning activities. The worldview formed is based upon criteria that experience has moulded as a means of interpreting a teacher's intentions, reliability and trustworthiness (Bretherton, 1987).

Self-Determination Theory (SDT) is a sociocultural motivational theory, involving the psychological and philosophical interplay of three basic psychological needs (BPNs) - relatedness, autonomy and competence (Ryan and Deci, 2000a). Relatedness is a basic psychological need, in that individuals have a "... psychological sense of being with others in secure communion or unity" (Ryan and Deci, 2002, p. 7). As a theory of human motivation and personality, SDT encompasses a continuum from proactive intrinsic motivation via passive extrinsic motivation to inactive amotivation. It has been empirically shown to be both predictive and indicative of an individual's sense of relatedness, perceived competence and behavioural regulation within classrooms as specific sociocultural environment (Reeve, 2002, 2012; Ryan and Deci, 2009). SDT differs from other sociocultural motivation theories in two distinct ways (Ryan and Deci, 2000). First, it emphasises the quality of the unseen motivational regulator as opposed to the quantity of the motivational regulator when considering the impact of different forms of motivation upon students' engagement with learning activities. A distinction is made between the different qualities of motivation, which range along a continuum from the most positive quality (self-determined motivation) to the most negative: a complete lack of motivation (amotivation) (Ryan and Deci, 2009, p.173). Second, it is the only sociocultural motivational theory that places the importance of autonomy as central, taking the form of an individual's self-regulated, volitional and sustained engagement during an activity.

Relatedness in the classroom involves the development of meaningful relationships with significant others, such as teachers and peers, through a sense of shared purpose and meaning (Painter, 2011). Competence is the psychological need to feel effective and confident within learning activities, so that students feel or perceive that they are capable of successfully performing within and completing a learning task (Ryan and Deci, 2002), and “... refers to the need to experience oneself as effective in one's interactions with the social and physical environments" (Skinner and Edge, 2002, p. 301). Perceived competence is a precursor that informs an individual's sense of selfefficacy in terms of perceived capability of achieving further competence within a specific domain or context, and self-agency, in the form of motivation to be autonomous and self-determined in working towards further competence. These perceptions, motivational drives and need for competence are at the heart of achievement motivation (Elliot and Dweck, 2007b). Therefore, perceived competence appears to be predictive of and predicted by self-efficacy and self-concept, with all three energizing self-regulated learning (Schunk and Zimmerman, 1989, 1998 , 2008). That is, an individual's self-efficacy has been shown as predictive of their motivation to be autonomous, and for the development of self-determined, self-regulating learners who are able to make the most of opportunities to enhance their competence, engagement and social mediation within the classroom (Bandura, 1986, 1997; Connell and Wellborn, 1991; Reeve, 2012; Reeve et al., 2008; Ryan and Deci, 2009). An individual's need for and satisfaction of autonomy is linked to their cognitive and affective perceptions of their ability to achieve self-determined or externally-regulated goals (Bandura, 1997). Therefore, perceptions of competence act as initiators of persistence, autonomy and sustained engagement during learning activities (Roberts et al., 1981). Autonomy is the psychological need to feel agentic through being able to exercise some freedom of choice and to make contributions to learning activities (Ryan and Deci, 2000), and “...refers to the need to express one's authentic self and to experience the self as the source of action" (Skinner and Edge, 2002, p. 298). Striving to feel that one can direct and organize one's behaviour, that one can choose and is not controlled and that one can develop and realize goals and values that feel authentic and give a sense of direction and meaning (from Kaplan and Assor, 2012, p. 253).

Children's perceptions of the teacher-student relationship quality appear to be influential predictors of children's engagement with learning activities (Hughes et al, 2008). Several studies have reported a specific relationship between teachers' interpersonal behaviours and students' positive engagement and attitudes to their learning in science (Ainley and Ainley, 2011ab; den Brok et al. 2005, 2006b; Lee and Anderson 1993).

Within the reviewed literature to date, there has been a plethora of research relating to specific teacher influences upon student engagement within schooling and the classroom in general. There is a wealth of empirical support for positively correlating student engagement as a predictor of academic achievement and motivated involvement within school in general (Connell and Wellborn, 1994; Finn, 1989; Klem and Connell, 2004; Voelkl, 1995, 1996, 1997). By comparison, there has been a paucity of research regarding domain-specific or subject-specific engagement factors in science. Despite such a paucity, engagement-enhancing factors specific to children's positive perceptions of science have been investigated within a number of prior studies (Abrahams, 2009, 2011; Abrahams and Millar, 2008; Ainley and Ainley, 2011a, 2011b; Blumenfeld and Meece; 1988; Darby, 2005; Lee and Anderson, 
1993; Lee and Brophy, 1996; Murphy et al., 2012). These have been reported, to varying degrees, that there are several common key elements central to an engaging science education, including teaching behaviours and approaches that promote autonomous learning and strong teacher-student interpersonal relationships. There was a further identified gap in the research in that vast majority of studies were only informed by data collected using questionnaires. However, the emergent common themes were rarely explored by researchers through discussions with students through focus group interviews. Finally, none of the prior research has involved the in-situ testing of SDT within a British school as means of identifying and understanding some of the key antecedents that inform students' engagement within science education. To date, the majority of research applying SDT within education has been situated in the USA. The current research has addressed the identified gaps.

\section{METHOD INCLUDING ANALYSIS}

Focus Group Interviews (FGIs) were used to harvest data which has enabled the researcher to gain an improved understanding of how knowledge, ideas, experiences, perceptions and expectations have been formed and what the sources of these are (Cronin, 2008). As Krueger (1998) asserts, the FGI, as with all qualitative research methods, should not be regarded as scientific research, in that the "... goal of qualitative research is to understand and communicate, not to control or replicate a study" (p. 64). Therefore, the focus group interviews (FGIs) were conducted as a means of gaining in-depth insights into the extent to which perceived competence and need for autonomy may or may not be affected by teacher-student relationship quality.

An FGI is "... a group interview or discussion" (Cronin, 2008, p. 227) which enables the discussion and exploration of respondents' views in depth. Within the current research, FGIs facilitated the exploration of students' perceptions and experience-informed interpretations of the engaging or disengaging nature of their learning environment. An advantage of utilising FGIs is that they provide a means of exploring students' responses in depth, alongside enabling respondents to determine how they respond to the exploration of their own perceptions and experiences. The dialogic interactions between the FGI participants enable the in-depth discussion of ideas, alongside elaboration through agreement or disagreement with the views of other respondents, and clarification of thinking. Whilst two people may agree and share the same perceptions and experiences, they may still differ in the words they use and the order in which responses are expressed. This includes being aware of the emphasis and intensity of responses, which also, invariably, differs between respondents.

The pilot study involved 10 students (none of whom took part in the formal FGI stage), with a range of openended questions being tested to ensure that these were non-ambiguous and easy to understand. Responses to the pilot questions were used to adapt the wording of the questions common to all FGIs and to ensure researcher neutrality, so that the questions could not be regarded as leading the respondents towards pre-determined views or responses (see Appendix A). In addition, a semi-structured approach was taken to enable unplanned questions to be asked if, for example, the researcher required clarification if he either did not understand responses or wished to explore them in greater depth.

\section{Analysis of the Transcribed FGIs}

The analysis of the FGIs was undertaken with a view to enabling external validity (generalisation) for science teachers wishing to apply the analysis outcomes within their own evidence-informed professional practice (Altricher et al., 1993; Kincheloe, 2001, 2005, 2012; Smyth, 1996; Thomas, 2002, 2004). Analysis of the FGIs was, therefore, focused through the research questions. Therefore, individual FGIs and the FGIs as a collective group were interrogated using Thematic Content Analysis protocols (TCA: Anderson, 1998, 2004). TCA enables the descriptive presentation of data collected using qualitative methods such as focus group interviews. The advantage of conducting a TCA is that the outcomes are descriptive and analytical (Cresswell, 2009; Fischer, 2006; Smith, 2008). However, TCAs are also a form of intuitive inquiry: a constructivist epistemology and ontology based upon the intersubjective, inferential interpretations of subjective data that has been focused by the interviewer's selection of questions and the order in which they are asked (Anderson, 1998, 2004). As TCA is a form of interpretive inquiry, the common points arising from the data analysis usually leads to far more questions than have been posed and answered (Aldridge et al., 1999, p. 50).

The transcribed FGIs were analysed in order to identify common themes across the year groups, to provide an overview of:

1. The self-reported affective, cognitive and self-attributional factors that students regard as being influential upon their engagement with learning;

2. The key motivating teacher characteristics and behaviours regarded as mediating influences upon the initiation and sustaining of engagement behaviours;

3. Specifically, the key teacher behaviours that; 
a. Inform students' views of the quality of the teacher-student interpersonal relationship during and outside science lessons;

b. Inform students' self-attribute perceptions, such as self-competence for learning science and self-efficacy within science lessons and activities, and;

c. Encourage or inhibit students' participation and autonomy within learning activities within the classroom and written assignments.

The emergent common themes are summarised in Appendix B.

\section{The Research Setting}

The research took place within an independent preparatory school in Great Britain. The headteacher and three science teachers gave their consent for timetabled science lessons to be set aside to allow students to participate in the FGIs. The children were mainly of white British origin, with parents, under the most recent social or socioeconomic classification, being of the elite and established middle classes (as defined by Savage et al., 2013). Science is taught as a general subject up until the end of Year Six (Fifth Grade), and from the start of Year Seven (Sixth Grade) to the end of Year Eight (Seventh Grade) the teaching and learning of science is separated into the scientific areas of biology, chemistry and physics.

\section{Selection of Participants for the Focus Group Interviews}

The FGI participants were selected so that there were, wherever possible, equal numbers of male and female students within each group. The children were interviewed in groups as the school's child protection policy stipulated that children should not be interviewed on a one-to-one basis within an enclosed space. In addition, the children were selected based upon their varying responses to topics covered within the aforementioned informal discussions, rather than their confidence levels or ability to articulate perceptions. Therefore, most FGI groups had six members as this would ensure that all of the selected children being able to discuss their perceptions as far as their individual confidence and articulacy enabled them to do so. With some groups, however, given the small class sizes, being rigid about the size of a focus group would have excluded one or two students. In this case, all of the students within the age group were included. One class group contained only male students, and therefore all nine male students from that group were interviewed. In total, 47 students participated: Group $1-6$ students aged 1011 (3 male, 3 female); Group 2 - 9 students aged 10-11 (all male); Group 3 - 8 students aged 11-12 (5 male, 3 female); Group 4 - 6 students aged 11-12 (3 male, 3 female); Group 5 - 6 students aged 12-13 (3 male, 3 female); Group 6 - 6 students aged 12-13 ( 3 male, 3 female), and; Group 7 - 6 students aged 12-13 (3 male, 3 female). Each group participated in one FGI, with each FGI lasting approximately 45 minutes. Each FGI was recorded and transcribed.

\section{RESULTS: Initial Analysis}

The analysis of results was focused through the research question: What do students regard as the key influences that have an impact upon their motivated engagement with learning activities? The key emergent themes are summarised in Table 1 and Appendix B. The perceived quality of the teacher-student relationship consistently emerged as the variable having the stronger impact upon students' motivation to engage with learning in science lessons. Students' perceived quality of the teacher-student relationship was influenced by their affective and cognitive responses and perceptions, mediated by their perceived competence. This, in turn, was influenced by the methods that individual science teachers had used to enhance students' feelings of self-competence during learning activities. Students self-reported their enhanced positive perceptions of their engagement with science. Across all cohorts and genders, such improvements were informed by positive changes to variables relating equally to relatedness, autonomy support and competence within science lessons. For example, when a group of 10 to 11 yearolds were asked about the role that the science teacher plays in motivating their engagement with learning activities, they affirmed that the teacher is the most important factor influencing and informing their enjoyment of science. This is due, according to the students, the teacher having the direct ability to particularly enhance the pace and depth of their perceived competence. 
Table 1. Summary of the themes discussed by students during the Focus Group Interviews: perceptions of SDT-related phenomena

\begin{tabular}{|c|c|c|c|c|c|c|c|c|c|c|c|c|c|c|c|c|c|}
\hline \multicolumn{5}{|c|}{ AGE GROUP } & \multicolumn{5}{|c|}{ RELATEDNESS } & \multirow{2}{*}{$\begin{array}{c}\begin{array}{c}\text { AUTONOMY } \\
\text { SUPPORT }\end{array} \\
\text { PAS }\end{array}$} & \multicolumn{4}{|c|}{ COMPETENCE } & \multicolumn{3}{|c|}{ ENGAGEMENT } \\
\hline & $\begin{array}{l}\text { TSIPRQ } \\
\text { within } \\
\text { lesson }\end{array}$ & $\mathrm{R}(\mathrm{TC})$ & PosTreat & NegTreat & SLikeT & SDislikeT & $\mathrm{R}(\mathrm{TS})$ & TExp & TSRExt & & PCom & SelfEff & SelfConf & ComStrat & $\begin{array}{l}\text { PosAffec } \\
\text { NegAffec }\end{array}$ & $\begin{array}{l}\text { CogEng } \\
\text { CogDiseng }\end{array}$ & $\begin{array}{l}\text { AcaEng } \\
\text { AcaDiseng }\end{array}$ \\
\hline $\begin{array}{l}\text { Group } 1 \\
\mathbf{1 0 - 1 1}\end{array}$ & $N(1)$ & & & - & & - & & $N-T N R C$ & $\mathrm{~N}$ & $\begin{array}{c}\mathrm{N}-\mathrm{I}, \mathrm{L} \\
\mathrm{N}-\mathrm{Tcont} \\
\mathrm{PCl}\end{array}$ & & P & & $N-1$ & $N$ & $\mathrm{~N}$ & $N$ \\
\hline Group 2 & $\mathrm{P}$ & & & & - & & P & & $\mathrm{P}$ & $P-1$ & $\mathrm{P}$ & P & P & $P-L$ & P & $\mathrm{P}$ & P \\
\hline Group 3 & V & & & & v & v & & & V & $V-1$ & $\mathrm{~N}$ & $P$ & $P$ & $P$ & V & V & V \\
\hline $11-12$ & & & & & & & & & & & & & & & & & \\
\hline Group 4 & $\mathrm{~V} / \mathrm{Imp}$ & & & & $\mathrm{P} / \mathrm{Imp}$ & & $\mathrm{P} / \mathrm{Imp}$ & & $\mathrm{P} / \mathrm{Imp}$ & $P / V$ & $\begin{array}{l}\mathrm{P} / \\
\mathrm{Imp}\end{array}$ & $\mathrm{P} / \mathrm{Imp}$ & P & $\mathrm{P} / \mathrm{Imp}$ & $\mathrm{P} / \mathrm{Imp}$ & $\mathrm{P} / \mathrm{Imp}$ & $\mathrm{P} / \mathrm{Imp}$ \\
\hline Group 5 & $\mathrm{~N}$ & $\mathrm{~N}$ & & $\bullet$ & & $\bullet$ & $\mathrm{N}$ & $N(A)$ & $\mathrm{N}$ & $N-1$ & $\mathrm{~N}$ & & $\mathrm{~N}$ & $\mathrm{~N}$ & $\mathrm{~N}$ & $\mathrm{~N}$ & $\mathrm{~N}$ \\
\hline $12-13$ & & & & & & & & & & & & & & & & & \\
\hline Group 6 & v & & - & & v & v & v & & v & $N-1$ & P & & P & P & v & v & v \\
\hline Group 7 & P & & & & & & & & $\mathrm{P}$ & A / Imp & $\begin{array}{l}\mathrm{P} / \\
\mathrm{Imp}\end{array}$ & & $\mathrm{P} / \mathrm{Imp}$ & $\mathrm{P} / \mathrm{Imp}$ & P & P & $P$ \\
\hline
\end{tabular}

Key: $\mathrm{P}=$ Positive responses / self-reported perceptions (mainly); $\mathrm{N}=$ Negative responses / self-reported perceptions (mainly); $\mathrm{V}=$ varied responses / self-reported perceptions: a mixture of positive and negative responses: I = Investigations; $\mathrm{L}=$ Lessons; $\mathrm{TCont}=$ Teacher Controlling; $\mathrm{PCl}=$ Preferred Choice within Investigations; $\mathrm{NI}=$ Not interesting; TNRC = Teacher Not Recognise / Acknowledge Student Competence; A = Ambiguity / Ambiguous; Imp = Improvement since last year.

Notes; Where a blank space has been left, the theme was either not discussed or insufficient information was available to form a perception as to whether the response was, on the whole, positive, negative or varied.

ABBREVIATIONS: TSIPRQ - Teacher-Student Interpersonal Relationship Quality; R(TC) = Relatedness (Teacher Care); PosTreat (Positive Treatment); NegTreat (Negative Treatment); SLikeT $=$ Students Like Teacher; SDislikeT (Student Dislikes Teacher); R(TS) = Relatedness (Teacher Support); TExp = Teacher Expectations; TSRExt = Teacher-Student Relationship external to science lessons; PAS = Perceived Autonomy Support; PCom = Perceived Competence; SelfEff = Self Efficacy; SelfConf = Self Confidence; ComStrat $=$ Strategies that have helped the students achieve success; PosAffec $=$ Positive Affect; NegAffec $=$ Negative Affect; CogEng = Cognitive Engagement; CogDiseng = Cognitive Disengagement; AcaEng = Academic Engagement; AcaDiseng = Academic Disengagement

The FGIs revealed that students' perceived competence was a vital precursor that influenced their motivatedinformed desire to be autonomous within learning activities. That is, more positive perceptions of perceived competence were associated with a stronger desire to be autonomous within learning activities. Whilst there was a weaker association between relatedness and autonomy support, the very strong correlative association between competence and autonomy support suggests that the students' perceptions of autonomy support may be enhanced by the students' perceived competence. The influence of perceived competence as the central variable of engagement and the development of positive teacher-student relationship quality was also posited by Archambault et al. (2013). They report that whilst a positive teacher-student relationship was a reliable predictor of sustained engagement across age groups, it was perceived competence that was the central variable informing engagement. Indeed, they suggest that "...trying to change the relationship a teacher shares with each student will be more challenging than attempting to alter student engagement" (p. 6).

A common response was that the students base their views of the quality of the teacher-student relationship (relatedness) upon their perceptions of the teacher's effectiveness at enhancing students' self-perceptions of competence as opposed to satisfying any wish they had for their teacher to be autonomy supportive. However, students often reported that they felt more positively about the quality of the teacher-student relationship when they were given opportunities to demonstrate and develop their subject-specific competence through the autonomous design and conducting of their own investigations.

\section{The Teacher-Student Relationship Quality (SDT: Relatedness)}

The students regarded teachers' relational behaviours, affective reactions and the feedback they provide during and following learning activities as central to their motivated and sustained engagement with science. These motivational perceptions, in turn, informed students' engagement with science through, for example, intrinsic interest, enjoyment, and, where the teacher made it possible, the exploration of students' ideas and understanding through inquiry-based learning. The quality of the teacher-student relationship was confirmed as cumulative outcomes of interactions. It was clear that the relationship quality was informed by the consistency of teachers' interactions with the students. For example, one student (aged 11-12) stated that, "...he's sometimes really nice to me, but then he sometimes gets really angry at me, for not much at all, so ... I'm a bit confused really, and so I don't really know". Another student, within the sane group, stated that, "last year, he could sometimes be very, very nice to me, and he could sometimes be very, very... I really, really hated him, and it was like so hard to tell if he liked me or not, sometimes I thought that he didn't really like me that much at all, and sometimes I thought that he sort of liked me...". Some of the 11 to 12 year-old students reported an ambiguity regarding the extent to whether their 
engagement within science lessons was based upon whether their perceptions of the teacher-student relationship were positive or negative. However, other 11 to 12 year-olds reported that the teacher was central to their enjoyment of and engagement with science. This viewpoint was articulated by a number of groups: that where there was a perceived positive quality to the teacher-student relationship, there were also positive perceptions of competence and autonomy within investigations. Stronger perceptions of positive relationships were sustained where the teacher was receptive to students' confidence levels and obvious competence, thereby enabling students to perceive themselves as more competent during learning activities. The students enjoyed and appreciated lessons where they had opportunities to demonstrate their competence through, for example, the discussion of their ideas, exploring their understanding of scientific concepts, and demonstrating their learning within practical activities. From the students' perspectives, teacher-student relationships were improved through science teachers' feedback that was regarded as positive. Such feedback included encouragement regarding the quality of work and the extent to which understanding of concepts has been gained. Feedback should also enable the correcting of misunderstandings and reinforcing the mastery of knowledge. Specific factors that influenced the students' perceptions that the teacherstudent relationship is a positive one included the teachers' ability to help students feel competent during science lessons.

All students, with the exception of one group, perceived a positive sense of competence and the motivation to be autonomous when a perceived positive teacher-student relationship was in place. The responses of the other group differed, in that whilst this group reported negative relationships with their current science teacher, these students still felt that they were learning more than they had with their previous science teacher. In this case, competence, despite the lack of a positive teacher-student relationship or enjoyment, was attributed more in terms of how the teacher taught the subject rather than the sense of relatedness that this particular group of students attributed to the teacher-student relationship.

\section{Autonomous Motivation (SDT: Autonomy)}

The students expressed their desire to be autonomous within learning activities, especially investigations. Further to changes of science teacher at the start of the academic year, many perceived a more positive teacherstudent relationship quality and motivation to be autonomous with their previous science teacher, comparative to their current teacher. All confirmed that the teacher was the most important factor influencing and informing their enjoyment of science. The students preferred having the choice as to whether they wanted the teacher to either direct the investigations or to allow them more freedom by, for example, encouraging them to be entirely selfdirecting. However, despite this factor having a positive influence upon their engagement with science, none of the focus groups felt that there were regular opportunities for them to exercise open-ended autonomy within investigations. Autonomy through inquiry-based learning, such as investigations, was important to the students as means of enhancing their perceived competence. All felt that, within their present science lessons, there were fewer opportunities for them to be autonomous than they would have liked. This did not, however, diminish their sense of perceived competence within science. Fewer, or indeed no, investigations had potentially resulted in missed opportunities for the children to learn or master concepts as autonomous and independent learners, especially where the children had been used to being so with their previous science teacher.

The students reported that the opportunities for autonomous inquiry-based activities were reduced as they progressed through the older age ranges within the school. The reason for this, in their opinion, was because, with the older cohorts, the teachers placed a greater emphasis upon the importance of acquiring competence and competence-related confidence through the understanding and retention of scientific concepts. One of the older groups stated that they would prefer a science teacher that teaches in such a way that students' feelings of competence were enhanced, especially as they were preparing for external examinations later in the academic year. However, this was not seen as a negative, as the students' preferred means of ensuring competence, understanding and retention whilst, for example, preparing for examinations was through on-going interactions and discussions with the teacher and with each other. This included the revision of previously encountered concepts through discussion with the science teacher: for example, “... I think [the current science teacher] is much better at explaining things than [the previous science teacher], because, [previous science teacher] kept just going on about things, and he didn't really explain them very well, so, I think [current science teacher] is a bit better, like at explaining them, and helping you understand".

\section{Perceived Competence (SDT: Competence)}

Students' perceived competence was enhanced when they are afforded opportunities to work together and help each other during learning activities. In addition, students expressed a universal desire to move on to new scientific concepts as and when they felt that they understood them, rather than always having to wait upon teachers' decisions to do so: for example, “...you are not spending ages on one subject, like you're not spending like five 
lessons ...you're only spending one lesson... because you have done it in much less time, and if you're just doing that every single time, in detail, it can get quite boring ...". Students felt their perceived competence was further enhanced by teachers who have a positive questioning style and that gave feedback which promoted further understanding of and confidence with concepts. Other means of enhancing students' perceived competence included students being given more time to investigate concepts, to develop their understanding and to complete work proficiently. The students preferred more direct input from their science teacher: careful explanations and feedback were welcomed by students as the basis for improving upon their current competencies, as long as it was accompanied by guidance upon how to improve. One student, for example, suggested that there was the need for more focused feedback upon the content of the work rather the presentation of the work: "I don't think he gives out enough feedback on what we've done" and "I know that he marked my work wrong, but he didn't explain it why, so, I didn't really know what to do".

\section{FURTHER ANALYSIS AND DISCUSSION}

For a classroom to stimulate engagement, students should perceive that there is a relevance and value to learning activities; a positive emotional climate within which students perceive a warm caring interpersonal relationship with their teacher; that the teacher is attuned and responsive to the individual responses and needs of students; that the students are making academic progress and are capable of making further progress (both independently and through teachers' autonomy-supportive behaviours), and; that the students enjoy their time in the classroom with that teacher (Pianta et al., 2012, p. 373; Reeve, 2009, 2012; Reeve and Halusic, 2009). Primarily, to promote a positive teacher-student relationship through the enhancement of students' perceived competence, teachers should aim to enhance students' abilities by recognising and celebrating their competence within current learning activities. This appears to be a basis for positive self-efficacious decisions when faced with further similar learning activities. These contextual factors are likely to have a reciprocal impact, in turn, upon students' perceived competence (Hipkins, 2012; Hughes et al., 2011; Lam et al., 2012).

Students' responses across the seven FGIs confirmed that perceptions of the quality of the teacher-student relationship were directly influenced by students' affective and cognitive perceptions of the methods that individual science teachers had used to enhance the students' perceived competence. Students reported that their teachers have the direct ability to enhance the pace and depth of the students' perceived competence. The students also confirmed that the teacher is the most important factor influencing and informing their enjoyment of and engagement with science. This was based upon a teacher's perceived ability to enhance the pace and depth of the students' perceived competence. In addition, responses revealed that they base their views of the quality of the teacher-student relationship upon their perceptions of the teacher's effectiveness at enhancing students' perceived competence. This was regarded as more important than satisfying any wish they had for their teacher to be autonomy supportive, with students' perceived competence influencing their motivation for learning during lessons.

It appears that such motivational influencers, if effectively afforded by teachers, should result in students being encouraged and supported to become more independent, self-competent and self-agentic learners who have positive perceptions of their self-efficacy. This, in turn, will inform their sustained desire to be autonomous (Bandura, 1986ab, 1997; Dewey, 1902. 1938ab; Vygotsky, 1978). This posit was supported by the students' responses to questionnaires across the three data waves, which revealed that the strongest correlative association informing their engagement was between relatedness and competence. The weakest correlative relationship informing their engagement was between relatedness and autonomy support.

During all FGIs, relatedness (the quality of the teacher-student relationship) emerged as the most influential SDT construct in terms of its impact upon students' motivated engagement with science learning activities. Students revealed that they based their views of the quality of the teacher-student relationship upon their perceptions of the teacher's effectiveness at enhancing students' perceived competence. Perceived competence was revealed as predictive of students' autonomous motivation during learning activities. It was also affirmed that the teachers were central to students' enjoyment of and engagement with science. The quality of the teacher-student relationship appears to be inextricably linked to the extent to which a teacher's behaviours and afforded learning provision during lessons promote the students' perceived competence specific to science, based upon repeated, confirmatory interactions. Students' perceived competence was based primarily upon the performance feedback provided by the teacher. Teachers' affordance of autonomy-supportive learning activities that were regarded as enjoyable, interesting and enjoyable also informed and predicted students' engagement with learning activities (Jang et al., 2012; Vansteenkiste et al., 2005, 2012). In addition, teacher care and affective support was revealed as a potential predictive basis for enhancing students' feelings of belonging, academic enjoyment, self-efficacy (perceived competence) and engagement (Hardre et al., 2006; Pat El et al., 2012; Zhou et al., 2012).

Student responses, therefore, confirmed that, whilst the satisfaction of all three SDT basic psychological needs is important, relatedness (positive teacher-student relationships) and competence are the two most influential SDT 
constructs upon their motivation to engage with science. As stated above, students' perceived competence was regarded as a stronger basis for a positive teacher-student relationship than satisfying any wish that the students had for their teacher to be autonomy supportive through, for example, the affordance of inquiry-based learning activities. However, where such opportunities were afforded, the students did confirm that this reinforced and promoted more positive perceptions of the quality of the relationship with their science teacher. Where students had increased and / or sustained opportunities to exercise their own autonomy through inquiry-based learning, they self-reported more positive perceived competence and progress in science. It may be that students who are afforded the autonomy to demonstrate their competence through, for example, inquiry-based learning activities, whilst supported by positive feedback from the science teacher, are more likely to develop a strong teacher-student relationship and, reciprocally, are more likely to be engaged with science. In addition, the reciprocal feedback perceptions of relatedness and competence have been asserted by students as having a direct impact upon their engagement with learning (within the main study, and, for example, Harter, 2012a; Mahatmya et al., 2012). The basis of this reciprocal relationship may be that perceived competence is influenced by an intrinsic motivation orientation, which, in turn, is informed by a student's perceptions that they have frequent opportunity to be autonomous and be supported in this by the teacher (Guay et al., 2013).

Feedback as a form of support by the teacher enhances perceived competence, which, in turn, appears to inform the quality of and balance between intrinsic and extrinsic forms of motivation (Deci and Moller, 2005; Ryan and Deci, 2009; Vallerand and Reid, 1984). The quality of the balance between intrinsic and extrinsic motivation determines the extent of engagement, as "Intrinsic motivation flourishes under conditions supporting autonomy and competence and wanes when these needs are thwarted" (Ryan and Deci, 2009, p. 174). Indeed, intrinsic motivation and other motivational variables are intrapersonal psychological responses to the sociocultural conditions of the classroom, including the teacher-student relationship quality (Hughes et al., 2008) and the regular enhancement of perceived competence during learning activities (Ryan and Deci, 2009). The nature of the learning activity will influence students' perspective of whether the activity encourages autonomy (such as inquiry-based open-ended learning) or controlling (such as a test of factual knowledge and retention, where motivation is more extrinsic than intrinsic (Benware and Deci, 1984; Fortier et al., 1995; Grolnick and Ryan, 1987). Perceived competence can still have a strong influence upon students' motivated engagement through the internalisation of an activity's value, such as its potential to lead to further cognitive progress (Ryan et al., 1985).

Relatedness, through the quality of the teacher-student relationship, has been referred to as a "supplement" within the SDT model, with autonomy and competence being more often emphasised as the basis for selfdetermined engagement (Ryan and Deci, 2009, p. 178). However, the current research suggests that relatedness is the essential central catalyst informing the quality of students' engagement through the enhancement of perceived competence. Students across all cohorts self-reported that they temporally developed a stronger sense of competence and autonomy support. This suggests that students are temporally able to develop positive perceptions of their competence and self-efficacy across the full continuum of teacher motivating styles from autonomy supportive to controlling (Close and Solberg, 2008).

From the results, of the three SDT constructs, the one that is most resilient with regards to engagement appears to be competence, in the form of an individual's sustained need and desire to be competent. This resilience was affirmed, even when the quality of the teacher-student relationship is regarded as negative and there are limited opportunities for students' autonomy to be exercised. Whilst none of the cohorts reported a consistent positive relationship with their science teacher, a small number of individuals within each group did report a positive relationship with the science teacher: in some cases, this was very positive. These students reported similarly positive perceptions of their competence within science learning activities, of positive levels of the autonomy allowed and, where afforded, autonomy support. However, with the increasing age of the groups it was interesting to note that although the quality of the teacher-student relationship was regarded overall as negative by the students there were still steady increases in the students' perceived competence and motivation to be autonomous. This suggests that whilst the teacher-student relationship quality appears to be predictive of students' perceived competence and autonomous motivation with younger students, the relationship may be less influential with the increasing age of the students as they developmentally move from dependence upon the teacher to interdependence (Harter, 2012a; Mahatmya et al., 2012; Ryan, 1982; Skinner and Pitzer, 2012). Also, it may be that younger students perceive the quality of the teacher-student relationship as being more important, comparative to their older peers, as the motivational basis for feeling engaged and competent within learning activities. It has been suggested that younger students' perceptions of the teacher-student relationship quality are based upon a form of learned helplessness: manifested as dependency upon the teacher for guidance, and for making the student's competence-based progress, successes and achievements overtly evident (Harter, 2012ab; Hattie, 2009, 2012; Pat El et al., 2012). As students mature, they usually become less dependent on their teacher (Harter, 2012a). However, there will still be adaptive help-seeking alongside an increasingly greater psychological need to be more independent, as well as engaging in tasks and behaviours where they increasingly feel more competent by making 
progress as a result of their own self-motivated and self-determined autonomy (Harter, 2012a; Mahatmya et al., 2012).

All groups reported their need to feel competent and to become more competent, even when the teacher-student relationship quality was viewed as negative. In addition, the positive affect generated in response to perceived and actual achievement was instrumental in enhancing students' perceived competence and, in turn, an a more positive teacher-student relationship quality. For example, enhanced engagement was observed during learning activities when there were positive associations between students' perceived competence and intrinsically regulated motivation (Cox and Williams, 2008). These motivated perceptions and increased engagement resulted in the student feeling more self-efficacious and, therefore, motivated and enthused by the challenges within new learning activities. This appears to be due to perceived competence and self-efficacy combining to create an overall academic self-concept which influenced the beliefs that the student has about their academic capabilities, skills and strengths, and the experiences that have informed these (Bandura, 1977, 1986ab, 1997; Cleary and Zimmerman, 2012; Hughes et al., 2011; Marsh and Shavelson, 1985; Pajares, 1996; Urdan and Turner, 2007).

It was interesting, also, that the students' regarded their perception of competence as sustaining their motivation for learning within science even if they did not always get the chance to translate this into autonomous behaviours often associated with optimum engagement. This differs from the findings of other studies that have focused upon the importance of the teacher-student relationship as the motivational basis for effortful engagement (Archambault et al., 2013; Birch and Ladd, 1997; Hamre and Pianta, 2006; Hughes et al., 2008; Pianta and Steinberg, 1992; Pianta and Stuhlman, 2004; Pianta et al., 1995, 2002, 2003). A possible reason for the responses of the current participants differing from those reported by other studies may be that they have learnt through experience to not only be less reliant upon the quality of the teacher-student relationship as the basis for informing their perceived competence but also at an earlier age than one would normally expect (Lynch and Cicchetti, 1997). The students' perceptions revealed that, rather than looking to their teachers, they had become more reliant upon their peers at this stage. They appeared to be using interactions with peers as an influential means of informing their perceived competence within science lessons. Although this could not be confirmed, it may be that the excellent quality of the teacher-student relationships that the children had when they were younger had helped them to internalise benchmarks for judging their perceived competence and self-efficacy earlier than one would expect developmentally. Indeed, Ryan (2001) highlighted the important compensatory role of peer influence, especially when the teacher-student relationship is either negative or regarded as less important, reporting that there is a tendency amongst young adolescents to group together according to perceived homophily: shared attributes including "...the norms, values, and standards that concern academic motivation and achievement. This shared peer group context is likely to influence adolescent motivation and engagement in school" (p. 1136).

Similar findings across FGIs revealed factors that were predictive of and are predicted by a positive teacherstudent relationship include a teacher who is;

1. receptive to students' perceived competence and self-confidence;

2. mindful of students' competence levels, allowing learning to progress at an appropriate pace;

3. adept at explaining scientific concepts and theories in such a way that all students may understand them;

4. providing opportunities for the students to discuss their ideas and explore their understanding of scientific concepts;

5. providing opportunities for the students to demonstrate their mastery, understanding and application of scientific concepts;

6. listening to students, acknowledging their ideas and questions; positive and encouraging in his feedback about a student's progress and competence, including the correction of misunderstandings;

7. perceived to be working hard to help students develop their competence and understanding of scientific concepts and processes;

8. treating all students fairly and equally, avoiding nepotism, and;

9. is adept at maintaining good relationships with students outside of science lessons.

Conversely, factors that are predictive of negative teacher-student relationships include a teacher who plans lessons in such a way that is very different from the way that the students prefer to learn; is perceived to make no effort to make learning enjoyable; who ignores the responses of students, particularly when they are attempting to demonstrate that they are already able to do something or have completed something prior within the current concept area, and; who does not allow sufficient time for the students to investigate concepts. Therefore, it is posited that the teacher-student relationship quality may be used as a reliable predictor of perceived competence, academic achievement, and educational outcomes such as sustained engagement with learning activities (Hattie, 2003). Furthermore, the current research suggests that the motivation to be autonomous is an outcome dependent upon the combined motivational impact of students' perceptions of the quality of the teacher-student relationship and 
their own perceived competence. The main study students self-reported that their perceptions of competence, especially where there was perceived negative relatedness, were attributed more to the means by which the teacher taught the subject and emphasised learning, rather than the sense of relatedness that this particular group of students attributed to the teacher-student relationship. As none of the focus groups felt that there were regular opportunities for them to design and lead open-ended, autonomous investigations, the perceived quality of the interpersonal relationship with the teacher had become increasingly dependent upon the extent to which the teacher directly enhanced the students' perceived competence during science lessons.

\section{CONCLUSIONS}

Whilst Ryan and Deci (2009) acknowledge that "... both the social-contextual and personal motivation variables central to SDT have been found to predict engagement, performance and well-being" (p. 181) and assert that relatedness, autonomy and competence have salient motivational influences upon an individual's self-determined motivation to engage with learning activities, they have not, within their writing, specified if one SDT construct is central to the positive psychosocial development of the other two when applied to students' motivated engagement in the classroom. The emergent multivariate hierarchical influences of each of the three SDT needs upon the other two and students' motivated engagement with learning is at the heart of the students' self-reported perceptions.

For a classroom to stimulate engagement, students should perceive that there is a positive emotional climate within which students perceive a warm caring interpersonal relationship with their teacher; that the teacher is attuned and responsive to the individual responses and needs of students; that the students are making academic progress and are capable of making further progress (both independently and through teachers' autonomysupportive behaviours), and; that the students enjoy the time they spend in the classroom with that teacher (Pianta et al., 2012, p. 373; Reeve, 2009, 2012; Reeve and Halusic, 2009). Primarily, in order to promote a positive cumulative and reciprocal teacher-student relationship through the enhancement of students' perceived competence, teachers should aim to support and encourage students through the enhancement of students' abilities to internalise the standards necessary for recognising and celebrating their competence within current learning activities. Such standards appear to act as a basis for positive self-efficacious decisions when faced with further similar learning activities. These contextual factors are likely to have a reciprocal impact, in turn, upon students' perceived competence (Hipkins, 2012; Hughes et al., 2011; Lam et al., 2012).

In summary, the students regarded their teachers as being central to the enhancement of students' engagement and achievement within learning activities (see Appendix B). This was based upon the view that the students perceived that the teacher has the direct ability to particularly enhance the pace and depth of the students' perceived competence, mediated by teacher feedback. Students' willingness to listen to and act upon competence-based feedback is informed by the perceived quality of the teacher-student relationship (Hipkins, 2012). Receptiveness to teacher feedback reciprocally informs students' self-efficacy, and, as a result, impacts upon their engagement within learning activities (Cleary and Zimmerman, 2012). The current research reveals that engagement is predictive of students' motivation, which is reliant upon the individual teacher satisfying the need for competence or autonomy, or both

From the FGIs, it appears that there is a potential hierarchy between SDT BPNs. However, the quality of the teacher-student relationship has been referred to as a 'supplement' within the SDT model, with autonomy and competence more often being emphasised as the basis for self-determined engagement (Ryan and Deci, 2009, p. 178). However, the evidence within the current research suggests that relatedness, in the form of positive teacherstudent relationships, is the essential catalyst informing the quality of students' engagement through the enhancement of perceived competence. The results of the school-based research suggest that the teacher behaviours and methods supporting students' perceived competence and motivation to be autonomous are optimized when students perceive that they have a positive relationship with the teacher within the classroom. Where there is a perceived positive teacher-student relationship, different forms of motivation were enhanced. These include intrinsic motivation, extrinsic motivation to work towards goals that are regarded as having a personal value, competence motivation and autonomous motivation (Hughes et al., 2008; Ryan and Deci, 2009). The desire for autonomy also appears to have a motivating impact upon perceived competence and the resultant competence motivation and intrinsic motivation to engage with learning. Students' motivation to exercise their own autonomy originated with the students' affect-driven feelings of perceived competence, self-agency and self-determination. Autonomy was self-reported as the least influential of the three SDT basic psychological needs in terms of its impact upon students' motivation to engage with learning activities.

A limitation of the current research was the sample size, which was necessarily small due to convenience sampling as the research was undertaken with the teacher-researcher's students. However, the seven focus group interviews effectively harvested a range of student perceptions, including the experiences and inferences that had shaped these, regarding the contextual factors and teacher behaviours that encouraged their motivated engagement with learning. Repetition of the study by teachers would enable the extension of each questionnaire to explore each 
area in greater depth. In addition, allowing more time to conduct FGIs may lead to greater insights regarding factors, experiences and perceptions that inform and influence students' self-perceptions. In addition, the presence of the researcher undoubtedly has an influence upon the behaviour of the people being studied, a phenomenon known as 'observer effect' (Cohen et al., 2007). However, as with most research designs, the researcher will never be successful in their attempts to eliminate their influence upon the people and settings they are studying and seeking to understand (Hakim, 2000, p. 67).

The current research has been approached throughout with the objective of enhancing teacher-researchers' contextual understanding of students' motivation to engage with learning activities. The discussed findings highlight areas that teachers may wish to focus their energies upon as means of enhancing the quality of the teacherstudent relationship and the students' perceived competence through a focus upon feedback. The findings may be applied by teachers within their own classrooms as a means of improving and developing both their evidenceinformed professional practice and further in-school research. The implications of this research are discussed herein in terms of the significance of the findings and their applicability as epistemological contributions to the substantive field of SDT within educational research. The findings have practical implications for teachers in their own classrooms, as well as school leaders and others involved in the formulation of educational policy based upon research-led teaching.

\section{REFERENCES}

Abrahams, I. (2009) Does Practical Work Really Motivate? A study of the affective value of practical work in secondary school science. International Journal of Science Education, 31(17), 2335-2353. https:/ / doi.org/10.1080/09500690802342836

Abrahams, I. (2011) Practical Work in Secondary Science: A Minds-On Approach. London: Continuum.

Abrahams, I., \& Millar, R. (2008). Does practical work really work? A study of the effectiveness of practical work as a teaching and learning method in school science. International Journal of Science Education, 30(14), 1945-1969. https:// doi.org/10.1080/09500690701749305

Ainley, M., \& Ainley, J. (2011a). Student engagement with science in early adolescence: The contribution of enjoyment to students' continuing interest in learning about science. Contemporary Educational Psychology, 36, 4-12. https:/ / doi.org/10.1016/j.cedpsych.2010.08.001

Ainley, M., \& Ainley, J. (2011b). A Cultural Perspective on the Structure of Student Interest in Science. International Journal of Science Education, 33(1), 51-71. https:/ / doi.org/10.1080/09500693.2010.518640

Aldridge, J. M., Fraser, B. J., \& Huang, T. I. (1999). Investigating Classroom Environments in Taiwan and Australia with Multiple Research Methods. Journal of Educational Research, 93(1), 48-62. https:/ / doi.org/10.1080/00220679909597628

Altricher, H., Posch, P., \& Somekh, B. (1993). Teachers Investigate their Work: An Introduction to the Methods of Action Research. London: Routledge.

Anderson, R. (1998). Intuitive inquiry: A transpersonal approach. In Braud, W. and Anderson, R. (eds.) Transpersonal research methods for the social sciences: Honoring human experience. (pp. 69-94). Thousand Oaks, CA: Sage.

Anderson, R. (2004). Intuitive inquiry: An epistemology of the heart for scientific inquiry. The Humanistic Psychologist, 32(4), 307-341. https:/ / doi.org/10.1080/08873267.2004.9961758

Archambault, I., Pagani, L. S., \& Fitzpatrick, C. (2013). Transactional associations between classroom engagement and relations with teachers from first through fourth grade. Learning and Instruction, 23, 1-9. https:/ / doi.org/10.1016/j.learninstruc.2012.09.003

Bandura, A. (1977). Self-efficacy: Toward a unifying theory of behavioral change. Psychological Review, 84, 191-215. https:/ / doi.org/10.1037/0033-295X.84.2.191

Bandura, A. (1986a). Social foundations of thought and action: A social cognitive theory. Englewood Cliffs, NJ: Prentice Hall.

Bandura, A. (1986b). The Explanatory and Predictive Scope of Self-Efficacy Theory. Journal of Social and Clinical Psychology, 3(4), 359-373. https:/ / doi.org/10.1521/jscp.1986.4.3.359

Bandura, A. (1997). Self-efficacy: The exercise of control. New York: Freeman.

Benware, C., \& Deci, E. L. (1984). Quality of learning with an active versus passive motivational set. American Educational Research Journal, 21, 755-765. https:// doi.org/10.3102/00028312021004755

Birch, S. H., \& Ladd, G. W. (1997). The Teacher-Child Relationship and Children's Early School Adjustment. Journal of School Psychology, 35(1), 61-79. https:/ / doi.org/10.1016/S0022-4405(96)00029-5 
Blumenfeld, P., \& Meece, J. L. (1988) Task factors, teacher behavior, and students' involvement and use of learning strategies in science. Elementary School Journal, 46, 26-43. https:/ / doi.org/10.1086/461536

Boggiano, A. K., \& Pittman, T. S. (Eds.) (1992). Achievement and Motivation: A Social-Developmental Perspective. Cambridge: Cambridge University Press.

Christenson, S. L., Reschly, A. L., \& Wylie, C. (2012). The Handbook of Research on Student Engagement. New York: Springer Science. https:/ / doi.org/10.1007/978-1-4614-2018-7

Cleary, T. J., \& Zimmerman, B. J. (2012). A Cyclical Self-Regulatory Account of Student Engagement: Theoretical Foundations and Applications. In S. L. Christenson, A. L. Reschly, \& C. Wylie (Eds.), The Handbook of Research on Student Engagement (pp. 237 - 257). New York: Springer Science. https://doi.org/10.1007/978-1-46142018-7_11

Close, W., \& Solberg, S. (2008). Predicting Achievement, Distress, and Retention among Lower-Income Latino Youth. Journal of Vocational Behavior, 72(1), 31-42. https:/ / doi.org/10.1016/j.jvb.2007.08.007

Connell, J. P. and Wellborn, J. G. (1994). Engagement Versus Disaffection: Motivated Patterns of Action In the Academic Domain. Rochester, NY: University of Rochester.

Cox, A., \& Williams, L. (2008). The roles of perceived teacher support, motivational climate, and psychological need satisfaction in students' physical education motivation. Journal of Sport and Exercise Psychology, 30, 222-239. https://doi.org/10.1123/jsep.30.2.222

Cresswell, J. W. (2009). Research Design: Qualitative, Quantitative, and Mixed Methods Approaches. (3rd edn.) Los Angeles, CA: SAGE.

Cronin, A. (2008). Focus Groups. In N. Gilbert (Ed.), Researching Social Life. (3rd edn.) Los Angeles, CA: SAGE.

Darby, L. (2005). Science Students' Perceptions of Engaging Pedagogy. Research in Science Education, 35, 425-445. https://doi.org/10.1007/s11165-005-4488-4

de Bilde, J., Vansteenkiste, M., \& Lens, W. (2011). Understanding the association between future time perspective and self-regulated learning through the lens of self-determination theory. Learning and Instruction, 21, 332344. https:/ / doi.org/10.1016/j.learninstruc.2010.03.002

Deci, E. L., \& Moller, A. C. (2005). The concept of competence: A starting place for understanding intrinsic motivation and self-determined extrinsic motivation. In, Elliot, A.J. and Dweck, C. (eds.) Handbook of Competence and Motivation (pp. 579-597) New York: Guilford Press.

Dewey, J. (1938a). Logic: The Theory of Inquiry. New York: Holt. Retrieved on 4th February 2018 from https:/ / archive.org/details/JohnDeweyLogicTheTheoryOfInquiry

Dewey, J. (1938b/1963). Experience and Education. New York: Collier Books.

Dewey, J. (1902/1990). The School and Society and the Child and the Curriculum. Chicago: The University of Chicago Press. https:// doi.org/10.7208/chicago/9780226112114.001.0001

Finn, J. D. (1989) Withdrawing from School. Review of Educational Research, 59(2), 117-142. https:/ / doi.org/10.3102/00346543059002117

Fischer, C. T. (ed.) (2006). Qualitative research methods for psychologists: Introduction through empirical studies. New York: Academic Press.

Fortier, M. S., Vallerand, R. J., \& Guay, F. (1995). Academic Motivation and School Performance: Toward a Structural Model. Contemporary Educational Psychology, 20, 257-274. https:/ / doi.org/10.1006/ceps.1995.1017

Fredricks, J. A., Blumenfeld, P. C., \& Paris, A. H. (2004). School Engagement: Potential of the Concept, State of the Evidence. Review of Educational Research, 74(1), 59-109. https:/ / doi.org/10.3102/00346543074001059

Fredricks, J. A., \& Eccles, J. S. (2002). Children's competence and value beliefs from childhood to adolescence: Growth trajectories in two "male-typed" domains. Journal of Developmental Psychology, 38, 519-533. https:/ / doi.org/10.1037/0012-1649.38.4.519

Grolnick, W. S. \& Ryan, R. M. (1987). Autonomy in children's learning: An experimental and individual difference investigation. Journal of Personality and Social Psychology, 52, 890-898. https://doi.org/10.1037/00223514.52.5.890

Guay, F., Ratelle, C., Larose, S., Vallerand, R. J., \& Vitaro, F. (2013). The number of autonomy-supportive relationships: Are more relationships better for motivation, perceived competence, and achievement? Contemporary Educational Psychology, 38, 375-382. https://doi.org/10.1016/j.cedpsych.2013.07.005

Hamre, B. K., \& Pianta, R. C. (2006). Student-Teacher Relationships. Retrieved on $4^{\text {th }}$ February 2018 from http:/ / www.pearweb.org/conferences/sixth/pdfs/NAS-CBIII-05-1001-005-hamre\%20\&\%20Pianta\%20 proof.pdf 
Harackiewicz, J. M., Manderlink, G., \& Sansone, C. (1992). Competence processes and achievement motivation: Implications for intrinsic motivation. In A. K. Boggiano and T.S. Pittman (Eds.), Achievement and Motivation: A Social-Developmental Perspective (pp. 115 - 137). Cambridge: Cambridge University Press.

Hardre, P. L., Chen, C-H., Huang, S-H. Chiang, C-T., Jen, F-L., \& Warden, L. (2006). Factors Affecting High School Students' Academic Motivation in Taiwan. Asia Pacific Journal of Education, 26(2), 189-207. https:// doi.org/10.1080/02188790600937326

Harter, S. (1992). The relationship between perceived competence, affect, and motivational orientation with the classroom: Processes and patterns of change. In In A. K. Boggiano and T. S. Pittman (Eds.), Achievement and Motivation: A Social-Developmental Perspective (pp. 77 - 114). Cambridge: Cambridge University Press.

Harter, S. (2012a). The Construction of the Self: Developmental and Sociocultural Foundations. (2nd edn) New York: The Guilford Press.

Harter, S. (2012b). Manual for the Self-Perception Profile for Adolescents (Revised Edition). Denver, CO: University of Denver. Retrieved on $1^{\text {st }}$ February 2018 from https:/ / portfolio.du.edu/SusanHarter/page/44210

Hattie, J. A. C. (2009). Visible Learning: A synthesis of over 800 meta-analyses relating to achievement. London: Routledge.

Hattie, J. A. C. (2012). Visible Learning for Teachers: Maximising Impact on Learning. London: Routledge. https:// doi.org/10.4324/9780203181522

Hipkins, R. (2012). The Engaging Nature of Teaching for Competency Development. In S. L. Christenson, A. L. Reschly and C. Wylie (Eds.), The Handbook of Research on Student Engagement. New York: Springer Science. https://doi.org/10.1007/978-1-4614-2018-7_21

Hughes, A., Galbraith, D., \& White, D. (2011). Perceived Competence: A Common Core for Self-Efficacy and SelfConcept? Journal of Personality Assessment, 93(3), 278-289. https:/ / doi.org/10.1080/00223891.2011.559390

Hughes, J. N., Luo, W., Kwok, O-M., \& Loyd, L. K. (2008). Teacher-student support, effortful engagement, and achievement: a 3-year longitudinal study. Journal of Educational Psychology, 100(1), 1-14. https:/ / doi.org/10.1037/0022-0663.100.1.1

Jang, H., Kim, E. J., \& Reeve, J. (2012). Longitudinal Test of Self-Determination Theory's Motivation Mediation Model in a Naturally Occurring Classroom Context. Journal of Educational Psychology, 104(4), 1175-1188. https://doi.org/10.1037/a0028089

Klem, A. M., \& Connell, J. P. (2004). Relationships Matter: linking Teacher Support to Student Engagement and Achievement. Journal of School Health, 74(7), 262-273. https:/ / doi.org/10.1111/j.1746-1561.2004.tb08283.x

Kincheloe, J. L. (2001). Describing the Bricolage: Conceptualizing a New Rigor in Qualitative Research. Qualitative Inquiry, 7(6), 679-692. https:/ / doi.org/10.1177/107780040100700601

Kincheloe, J. L. (2005). On to the Next Level: Continuing the Conceptualization of the Bricolage. Qualitative Inquiry, 11(3), 323-350. https:/ / doi.org/10.1177/1077800405275056

Kincheloe, J. L. (2012). Teachers as researchers: Qualitative inquiry as a path to empowerment. (3rd edn.) London: Falmer. https://doi.org/10.4324/9780203801550

Krueger, R. A. (1998). Analyzing and Reporting Focus Group Results. Thousand Oaks, CA: SAGE. https:/ / doi.org/10.4135/9781483328157

Lee, O., \& Anderson, C. W. (1993). Task engagement and conceptual change in middle school science classrooms. American Educational Research Journal, 30, 585-610. https:/ / doi.org/10.3102/00028312030003585

Lee, O., \& Brophy, J. (1996). Motivational patterns observed in sixth-grade science classrooms. Journal of Research in Science Teaching, 33, 585-610. https://doi.org/10.1002/(SICI)1098-2736(199603)33:3<303::AIDTEA4>3.0.CO;2-X

Lynch, M., \& Cicchetti, D. (1997). Children's relationships with adults and peers: An examination of elementary and junior high school students. Journal of School Psychology, 35, 81-99. https://doi.org/10.1016/S00224405(96)00031-3

Mahatmya, D., Lohman, B. J., Matjasko, J. L., \& Feldman Farb, A. (2012). Engagement across Developmental Periods. In S. L. Christenson, A. L. Reschly and C. Wylie (Eds.), The Handbook of Research on Student Engagement (pp. 45 - 63). New York: Springer Science. https://doi.org/10.1007/978-1-4614-2018-7_3

Marsh, H. W., \& Craven, R.G. (2006). Reciprocal Effects of Self-Concept and Performance from a Multidimensional Perspective: Beyond Seductive Pleasure and Unidimensional Perspectives. Perspectives on Psychological Science, 1, 133-163. https:/ / doi.org/10.1111/j.1745-6916.2006.00010.x

Marsh, H. W., Craven, R., \& Debus, R. (1998). Structure, Stability, and Development of Young Children's SelfConcepts: A Multicohort-Multioccasion Study. Child Development, 69(4), 1030-1053. 
Marsh, H. W., \& Martin, A. J. (2011). Academic self-concept and academic achievement: Relations and causal ordering. British Journal of Educational Psychology, 81, 59-77. https:/ / doi.org/10.1348/000709910X503501

Marsh, H. W., \& O'Mara, A. (2008). Reciprocal Effects between Academic Self-Concept, Self-Esteem, Achievement, and Attainment Over Seven Adolescent Years: Unidimensional and Multidimensional Perspectives of SelfConcept. Personal and Social Psychology Bulletin, 34, 542-552. https:/ / doi.org/10.1177/0146167207312313

Marsh, H. W., \& Shavelson, R. J. (1985). Self-concept: Its multifaceted, hierarchical structure. Educational Psychologist, 20, 107-125. https://doi.org/10.1207/s15326985ep2003_1

Martin, M. O., Mullis, I. V. S., Beaton, A. E., Gonzalez, E. J., Smith, T. A., \& Kelly, D. L. (1997). Science Achievement in the Primary School Years: IEA's Third International Mathematics and Science Study (TIMSS). Chestnut Hill, MA: TIMSS \& PIRLS International Study Center, Boston College.

Martin, M. O., Mullis, I. V. S., Gonzalez, E. J., \& Chrostowski, S. J. (2004). Findings from IEA's Trends in International Mathematics and Science Study at the Fourth and Eighth Grades. Chestnut Hill, MA: TIMSS \& PIRLS International Study Center, Boston College.

Martin, M. O., Mullis, I. V. S., \& Foy, P. (2008). TIMSS 2007 International Science Report: Findings from IEA's Trends in International Mathematics and Science Study at the Fourth and Eighth Grades. Chestnut Hill, MA: TIMSS \& PIRLS International Study Center, Boston College.

Martin, M. O., Mullis, I. V. S., Foy, P., \& Stanco, G. M. (2012). TIMSS 2011 International Results in Science. Chestnut Hill, MA: TIMSS \& PIRLS International Study Center, Boston College.

Murphy, C., Varley, J., \& Veale, O. (2012) I'd rather they did experiments with us... than just talking: Irish children's views of primary school science. Journal of Research in Science Education, 41(3), 415-438. https:/ / doi.org/10.1007/s11165-010-9204-3

OECD (2000). Education at a Glance: OECD Indicators. Paris: OECD. https:/ / doi.org/10.1787/eag-2000-en

OECD (2007). PISA 2006 Science Competencies for Tomorrow's World Volume 1: Analysis. Paris: OECD.

OECD (2010). PISA 2009 Results: What Students Know and Can Do (Volume 1). Paris: OECD.

OECD (2013). PISA 2012 Results: Ready to Learn Students' Engagement, Drive and Self-Beliefs. Volume III. Paris: OECD.

Painter, J. (2011). Autonomy, Competence, and Intrinsic Motivation in Science Education: A Self-Determination Theory Perspective (Unpublished Ph.D. thesis), University of North Carolina.

Pajares, F. (1996). Self-efficacy beliefs in achievement settings. Review of Educational Research, 66, 543-578. https:// doi.org/10.3102/00346543066004543

Park, S., Holloway, S. D., Arendtsz, A., Bempechat, J., \& Li, J. (2012). What makes students engaged in learning? A time-use study of within- and between-individual predictors of emotional engagement in low-performing high schools. Journal of Youth and Adolescence, 41(3), 390-401. https:/ / doi.org/10.1007/s10964-011-9738-3

Pat El, R., Tellima, H., \& van Koppen, S. W. (2012). Effects of Formative Feedback on Intrinsic Motivation: Examining Ethnic Differences. Learning and Individual Differences, 22(4), 449-454. https:/ / doi.org/10.1016/j.lindif.2012.04.001

Pianta, R. C., Hamre., \& Stuhlman, M. (2003). Relationships between teachers and children. In W. Reynolds \& G. Miller (Eds.), Comprehensive Handbook of Psychology: Vol.7 (pp. 199 - 234). New York: Wiley.

Pianta, R. C., \& Steinberg, M. S. (1992). Teacher-Child Relationships and the Process of Adjusting to School. New Directions for Child Development, 57, 61-80. https:/ / doi.org/10.1002/cd.23219925706

Pianta, R. C., Steinberg, M. S., \& Rollins, K. B. (1995). The first two years of school: Teacher-child relationships and deflections in children's classroom adjustment. Development and Psychopathology, 7, 295-312. https:/ / doi.org/10.1017/S0954579400006519

Pianta, R. C., \& Stuhlman, M. W. (2004). Teacher-child relationships and children's success in the first years of school. School Psychology Review, 33(3), 444-458.

Pianta, R. C., Stuhlman, M. W., \& Hamre, B. K. (2002). How school can do better: Fostering stronger connections between teachers and students. New Directions for Youth Development, 93, 91-107. https://doi.org/10.1002/yd.23320029307

Reschly, A. L., \& Christenson, S. L. (2006). Prediction of dropout among students with mild disabilities: A case for the inclusion of student engagement variables. Remedial and Special Education, 27, 276-292. https:/ / doi.org/10.1177/07419325060270050301

Reschly, A. L., \& Christenson, S.L. (2012). Jingle, Jangle, and Conceptual Haziness: Evolution and Future Directions of the Engagement Construct. In S. L. Christenson, A. L. Reschly and C. Wylie (Eds.), The Handbook of Research on Student Engagement (pp. 3 - 20). New York: Springer Science. https:/ / doi.org/10.1007/978-1-4614-20187_1 
Reeve, J. (2002). Self-Determination Theory Applied to Educational Settings in E. L. Deci, \& R. M. Ryan (Eds.), Handbook of Self-Determination Research (pp. 183 - 204). Rochester, NY: The University of Rochester Press.

Reeve, J. (2012). A Self-determination Theory Perspective on Student Engagement. In S. L. Christenson, A. L. Reschly and C. Wylie (Eds.), The Handbook of Research on Student Engagement (pp. 149 - 172). New York: Springer Science. https:/ / doi.org/10.1007/978-1-4614-2018-7_7

Ryan, A. (2001). The Peer Group as a Context for the Development of Young Adolescent Motivation and Achievement. Child Development, 72(4), 1135-1150. https:/ / doi.org/10.1111/1467-8624.00338

Ryan, R. M. (1982). Control and information in the intrapersonal sphere: An extension of cognitive evaluation theory. Journal of Personality and Social Psychology, 43, 450-461. https:/ / doi.org/10.1037/0022-3514.43.3.450

Ryan, R. M., Connell, J. P. \& Deci, E. L. (1985). A motivational analysis of self-determination and self-regulation in education. In Ames, C. and Ames, R.E. (eds.) Research on motivation in education: The classroom milieu. New York: Academic Press.

Ryan, R. M., \& Deci, E.L. (2000a). Self-Determination Theory and the Facilitation of Intrinsic Motivation, Social Development, and Well-Being. American Psychologist, 55(1), 68-78. https://doi.org/10.1037/0003066X.55.1.68

Ryan, R. M., \& Deci, E. L. (2000b). Intrinsic and extrinsic motivations: Classic definitions and new directions. Contemporary Educational Psychology, 25, 54-67. https:/ / doi.org/10.1006/ceps.1999.1020

Ryan, R. M., \& Deci, E. L. (2009). Promoting Self-Determined School Engagement; Motivation, Learning and WellBeing. In K. R. Wentzel, \& A. Wigfield (Eds.), Handbook of Motivation at School (pp. 171 - 196). New York: Routledge.

Savage, M., Devine, F., Cunningham, N., Taylor, M., Li, Y., Hjellbrekke, J., Le Roux, B., Friedman, S., \& Miles, M. (2013). A New Model of Social Class? Findings from the BBC's Great British Class Survey Experiment. Sociology, 47(2), 219-250. https:/ / doi.org/10.1177/0038038513481128

Schunk, D. H., \& Pajares, F. (2005) Competence Perceptions and Academic Functioning. In Elliot, A.J. and Dweck, C.S. (eds.) (2005) Handbook of Competence and Motivation. New York: London.

Seligman, M. E. P., \& Altenor, A. (1980). Learned Helplessness. Behaviour Research and Therapy, 18(5), 462-473. https://doi.org/10.1016/0005-7967(80)90012-1

Skinner, E. A., \& Belmont, M. J. (1993). Motivation in the Classroom: Reciprocal Effects of Teacher Behavior and Student Engagement across the School Year. Journal of Educational Psychology, 85(4), 571-581. https:/ / doi.org/10.1037/0022-0663.85.4.571

Skinner, E. A., \& Pitzer, J. R. (2012). Developmental Dynamics of Student Engagement, Coping and Everyday Resilience. In S. L. Christenson, A. L. Reschly and C. Wylie (Eds.), The Handbook of Research on Student Engagement (pp. 21 - 44). New York: Springer Science. https://doi.org/10.1007/978-1-4614-2018-7_2

Smith, C. P. (ed.) (2008). Motivation and personality: Handbook of thematic content analysis. Cambridge: Cambridge University Press.

Smyth, J. (1996). Developing socially critical educators. In Boud, D. \& Miller, N. (eds.) (1996) Working with Experience: Animating learning. (pp. 27 - 40). London: Routledge.

Thomas, G. (2002). Theory's Spell: On Qualitative Inquiry and Educational Research. British Educational Research Journal, 28(3), 419-434. https:/ / doi.org/10.1080/01411920220137476

Thomas, G. (2004). Introduction: evidence and practice. In Thomas, G. and Pring, R. (eds.) (2004) Evidence-Based Practice in Education. Maidenhead, Berkshire: Open University Press.

Tymms, P., Bolden, D., \& Merrell, C. (2008). Science in English primary schools: trends in attainment, attitudes and approaches. In Perspectives on Education: Primary Science. Issue 1, September 2008. London; Wellcome Trust.

Urdan, T., \& Turner, J. C. (2007). Competence Motivation in the Classroom. In A. J. Elliot, \& C. S. Dweck (Eds.) Handbook of Competence and Motivation (pp. 297-317). New York: The Guilford Press.

Vallerand, R. J., \& Reid, G. (1984). On the causal effects of perceived competence on intrinsic motivation: A test of cognitive evaluation theory. Journal of Sport Psychology, 6, 94-102. https://doi.org/10.1123/jsp.6.1.94

Vansteenkiste, M., Sierens, E., Goossens, L., Soenens, B., \& Dochy, F. (2012). Identifying Configurations of Perceived Teacher Autonomy Support and Structure: Associations with Self-Regulated Learning, Motivation and Problem Behavior. Learning and Instruction, 22(6), 431-439. https:// doi.org/10.1016/j.learninstruc.2012.04.002

Vansteenkiste, M., Simons, J., Lens, W., Soenens, B., \& Matos, L. (2005). Examining the Motivational Impact of Intrinsic Versus Extrinsic Goal Framing and Autonomy-Supportive Versus Internally Controlling 
Communication Style on Early Adolescents' Academic Achievement. Child Development, 76(2), 483-501. https:/ / doi.org/10.1111/j.1467-8624.2005.00858.x

Voelkl, K. E. (1995) School Warmth, Student Participation, and Achievement. Journal of Experimental Education, 63, 127-138. https:/ / doi.org/10.1080/00220973.1995.9943817

Voelkl, K. E. (1996) Measuring Students' Identification with School. Educational and Psychological Measurement, 56, 760-770. https:// doi.org/10.1177/0013164496056005003

Voelkl, K. E. (1997) Identification with schools. American Journal of Education, 105, $294-318$. https:/ / doi.org/10.1086/444158

Vygotsky, L. S. (1978). Mind in Society: The Development of Higher Psychological Processes. Cambridge, MA: Harvard University Press.

Willms, J. D. (2003). Student Engagement at School: A Sense of Belonging and Participation. Results from PISA 2000. Paris: OECD. Retrieved on $8^{\text {th }}$ October 2017 from http:/ / www2.unb.ca/crisp/pdf/0306.pdf

Zhou, N., Lam, S-F., \& Chan, K. C. (2012) The Chinese Classroom Paradox: A Cross-Cultural Comparison of Teacher Controlling Behaviors. Journal of Educational Psychology, 104(4), 1162-1174. https://doi.org/10.1037/a0027609 


\section{APPENDIX A}

\section{Examples of Questions Asked and Areas Explored during the Focus Group Interviews}

- Describe how well you get on with your current Science teacher, outside the Science lesson.

- Do you have much contact with him outside of your Science lessons? Do you see him for other lessons, or for other activities?

- Do you think that liking your Science teacher outside of the Science lesson makes a difference to how you feel about Science lessons at all?

- Would you say that your perceptions of your teacher affect how you enjoy Science?

- If you had that choice, would you have your previous Science teacher back, or would you stick with the one you've got now?

- Did your perceptions change over time? If they did, what might have caused those changes in your perceptions?

- If you're not feeling happy within Science lessons, what have your science teachers done to help?

- What would your ideal Science teacher be like? What would you want from your ideal Science teacher?

- Does your Science teacher listen to you? Do they use your ideas, and do you feel that your Science teacher is listening to you?

- Do you feel able to say to your current Science teacher, "Can we have a lesson where we can show you that we have actually learned this?" Would you be able to do that?

- Are you given lots of opportunities to discuss your ideas and thinking, or are you expected to have the right answer?

- What do you like most about your Science lessons?

- Do you get opportunities to design, and do your own investigations? Does that make a difference to your enjoyment of Science lessons?

- What would be your ideal Science lesson?

- Is the teacher the most important factor in your enjoyment of Science?

- How does your Science teacher help you to feel more confident within Science?

- How does your current Science teacher use feedback in terms of how well you're doing?

- Does this help you to feel more competent, and that you are doing well within your Science?

- In what ways has your Science teacher helped you to understand what you're learning? How do they help you as individuals?

- What could your teacher do to make the relationship between you and him stronger within the Science lessons?

- Is it important to like your Science teacher, and your Science teacher to like you, to make a difference to your enjoyment and your progress within the lessons?

- Is there anything else that you want to say about your enjoyment or improvement of Science, anything like that, that I haven't asked you about, or that you haven't had the opportunity to discuss?

- Does your current Science teacher's feedback help you to feel more competent during science lessons? 


\section{APPENDIX B}

\section{Summary of Characteristics of Students' SDT-Grounded Engagement with Learning in Science}

\section{The influence of the interplay between the three SDT basic needs}

1. There is an emerging important relationship, in terms of the influence that relatedness, in the form of teachers' support behaviours, has upon students' perceived competence, intrinsic motivation, and motivation for engagement and achievement.

2. Students' classroom-based perceptions of teacher support (relatedness) influenced student's perceived competence, with both being predictive of students' motivation to engage in learning: a student's individual affect and motivation to engage with learning activities are based upon his/her perceptions of the classroom environment.

3. Motivation for learning takes many forms, including intrinsic, self-determined, extrinsic and amotivation, and are functions of and dependent upon age, mediated by students' perceptions of the teacher and teacherprovided support;

4. Regardless of age, perceived competence and the perceived satisfaction of competence emerged as the strongest mediators between the teacher-student relationship (relatedness) and self-determined motivation and engagement in learning;

5. Perceived competence was based upon performance feedback provided by the teacher, which, in turn, informed students' need for autonomy;

6. Both relatedness and competence, but not autonomy, mediate the effect of feedback upon students' motivation: the extent to which a student regarded feedback as either positive or negative was dependent upon the perceived quality of the interpersonal relationship with the teacher and the extent to which the teacher's feedback informs a student's positive perceived competence;

\section{Perceived competence and the influence upon self-efficacy}

7. Common across the age range cohorts was the association between higher levels of perceived competence and higher self-efficacy, higher self-esteem, and higher competence need satisfaction: this was equally associated with higher levels of self-determined motivation and intrinsic motivation;

8. Key factors which were asserted as mediating between social contextual factors provided the teacher and students' sustained engagement were the provision of learning activities which promote students' positive perceptions of competence and self-efficacy

9. Competence support by the teacher was central to students' expectancy-related and self-efficacious beliefs;

10. Perceived competence has the potential to inform students' self-efficacy, and, in consequence, impact upon their engagement within learning activities;

11. Relatedness and competence have a mediational influence upon students' motivational perceptions and reactions predictive of engagement;

12. Prior academic self-concept significantly predicted academic achievement, which is potentially mediated by students' perceived competence.

\section{Relatedness through the quality of the teacher-student interpersonal relationship}

13. There was an emphasis upon the importance of the teacher's role in ensuring that all of these factors are sustained through their interpersonal and instructional styles;

14. The strength of the social relationship with the teacher was more influential upon students' motivation for and engagement with learning, comparative to the students' perceptions of autonomy and competence:

a. All three SDT constructs were found to partially mediate self-determined engagement with learning through the quality of the teacher-student relationship.

b. A teacher's interpersonal style and associated behaviours had a long-term impact upon students' SDT basic need satisfaction, adjustment to learning within a formal context, and an enhanced sense of the desire to engage in learning;

c. Relatedness through teacher support was the basis of the teacher-student relationship quality;

d. Social-contextual factors afforded by the teacher within the classroom enable students to satisfy their basic needs for relatedness, competence and autonomy; 
e. Affective support by teachers is a sound basis for enhancing feelings of belonging, academic enjoyment, academic optimism and self-efficacy (perceived competence) and engagement (academic effort).

f. Significant associations were reported between perceived teacher affective support and students' motivational, affective and engagement behaviour outcomes.

g. Teachers' positive affective support behaviours include caring for and interest in students, demonstrating respect and concern as appropriate, listening and responding to students' ideas, recognition of effort, and fair treatment: these are argued to be positive predictors of students' optimistic self-concept, academic effort, academic achievement, and the pursuit and practise of prosocial behaviours.

h. Relatedness-enhancing behaviours were the basis of the development of higher expectations of students, and were associated together: that is, a teacher who felt a stronger affective / relational bond with a student had higher expectations of the student than, conversely, where the teacher felt a weaker affective / relational bond.

i. The positive teacher-student interpersonal relationship develops through frequent interactions with teachers during collaborative projects, focus upon relationship enhancement, modelling enthusiasm for and confidence in students' ideas, providing academic and emotional support which result in regular opportunities to achieve success, and provide informative feedback in a positive manner, including what was done well, and what may be done next to achieve further competence and success.

15. There were positive associations between teacher support, enhanced feelings of relatedness towards the teacher, and students' feelings of self-determined motivation;

\section{The need for autonomy and factors informing perceptions of autonomy supportive behaviours}

16. Autonomy support and engagement may be enhanced over time, mediated by relatedness enacted as teacher support. Reciprocal effects were found between earlier perceptions of engagement and later perceptions of the motivating and engaging nature of the classroom.

17. Students who perceived a higher level of autonomous self-determination, as opposed to feeling controlled by their teacher, were more likely to feel that all of their SDT basic needs were being satisfied as a direct result of their teacher's behaviours;

18. There is a positive relationship between students' subject-specific science achievement, intrinsic motivation for and engagement with learning in science lessons, which are influenced by perceptions of autonomy support and perceived subject-specific competence in science;

19. Intrinsic motivation has a positive influence upon subject-specific self-concept, such as perceived competence and self-efficacy, and, in turn, achievement, and further enhanced perceptions of autonomous motivation, engagement and achievement over time;

20. The need to be autonomous may be a motivational outcome of the combination of teachers' relationalenhancing behaviours and the extent to which teachers' competence-based feedback enhances students' perceived competence.

21. Teachers' autonomy supportive behaviours have a positive mediating influence upon intrinsic motivation via the influence of perceived competence;

22. Students' perceptions of teachers' autonomy supportive behaviours was predicted by autonomous motivation, dependent upon whether goals are perceived by students as intrinsic or extrinsic

23. Relatedness and autonomy support can enhance students' enhanced positive perceptions of higher need satisfaction, self-determined motivation and engagement;

\section{Teachers' behaviours supportive of enhancing students' positive engagement with learning}

24. Teachers should afford and create an optimal learning context which enhances students' affective perceptions of well-being and the motivation to persistently engage in learning;

25. Teachers who deliberately increase the frequency of behaviours regarded as being central to the three SDT constructs can enhanced their students' quality of motivation and their subsequent wish to engage further in learning;

26. Teacher-student interactive dialogue supports students' sense of autonomy and competence:

a. Teachers' performance feedback had an impact upon students' sense of relatedness and intrinsic motivation for engaging in learning activities;

b. Key mediating variables that have an impact upon intrinsic motivation and subsequent engagement were the teachers' interpersonal style and instructional behaviours during lessons, and the influence of these upon students' motivational needs; 
27. Perceptions of relatedness are enhanced by teachers' supportive dialogue that is meaningful to the student;

a. allowing students to take leadership roles within the classroom;

b. involving students in decision making;

c. affording a motivational climate that emphasises the competence of students;

d. encouraging students to develop their perceived competence as the basis for becoming more selfefficacious when approaching new learning activities, and;

e. positive, autonomy-encouraging phrases, such as "You could" and "You might", as opposed to "You should" and "You must", when used by teachers will be regarded as more autonomy supportive, and therefore more motivating and predictive of engagement, than controlling.

28. Teacher support manifested as autonomy supportive behaviours were positively predictive of intrinsic motivation and self-determined motivation to engage with learning activities.

\section{http://www.ejmste.com}

